\title{
Triple-Notched Band CPW fed UWB Antenna with Metallic Reflector for High Gain Performance
}

\author{
K.G. Jangid ${ }^{1}$, P.K.Jain ${ }^{2}$, B. R. Sharma ${ }^{3}$, V.K.Saxena ${ }^{2}$, V.S.Kulhar ${ }^{1}$, D. Bhatnagar ${ }^{2}$ \\ ${ }^{1}$ Department of Physics, Manipal University, Jaipur, India-303007 \\ ${ }^{2}$ Microwave Lab, Department of Physics, Jaipur, India-302004 \\ ${ }^{3}$ Department of Physics, SKITM\&G, Jaipur, India-302017 \\ *corresponding author, E-mail: kgkris1980@rediffmail.com
}

\begin{abstract}
This paper exhibits the design and performance of a coplanar waveguide (CPW) fed triple notched band ultrawide band (UWB) antenna. Proposed prototype has two Ushaped slots on the patch and an inverted U slot in feed line with a metal reflector beneath the radiating element. Proposed structure renders wider impedance bandwidth extended between frequencies $2.71 \mathrm{GHz}$ to $12.92 \mathrm{GHz}$ for VSWR $<2$ with three rejection bands in the frequency ranges 3.456 to $3.988 \mathrm{GHz}$ (WI-MAX IEEE 802.16), 5.27 to $6.032 \mathrm{GHz}$ (WLAN IEEE $802.11 \mathrm{a} / \mathrm{h} / \mathrm{j} / \mathrm{n}$ ) and 7.88 to $8.65 \mathrm{GHz}$ (X-band down link satellite system) for VSWR > 2. The utmost simulated gain of proposed antenna with reflector is close to $9.9 \mathrm{dBi}$ at $7.4 \mathrm{GHz}$. A sharp reduction observed in the efficiency values of the proposed structure at stop bands. Perhaps, this structure proved as a useful tool for various applications in modern communication systems including UWB.
\end{abstract}

\section{Introduction}

The outspread bandwidth of ultra wideband technology is extensively preferred by academia and industry due to its credible usage in high-speed data transfer and microwave imaging [1-2]. In 2002, the Federal Communications Commission (FCC) released an unlicensed band for commercial use in radio communications in the frequency range of 3.1-10.6 GHz. Since permitted power emission level of UWB band is quite low so this band is easily interfered by other adjoining high power communications systems such as WiMAX communication system, WLAN communication system, and ITU X-band communication. The disruptions of these high power communication systems with UWB communication systems can evade by applying the band rejection filter [3]. Many UWB antennas with band-notched characteristics proposed in the literature [4-13]. Zarrabi [4] reported a triple notch band UWB antenna that had a fractal Koch structure with a T-shaped stub. The central frequency of these notch bands is $2 \mathrm{GHz}$, 3.5 GHz, and 5.8 GHz subsequently. M. Sharma [5] presented an Urn-shaped UWB antenna along with T-shape stub and two $\mathrm{C}$-shaped slots resulted in a triple notch band with central frequencies allocated for WI-MAX IEEE 802.16, WLAN IEEE $802.11 \mathrm{a} / \mathrm{h} / \mathrm{j} / \mathrm{n}$ and X-band down link satellite systems. Syed and Aldhaheri [6] proposed a CPW fed UWB antenna with eliminating IEEE 802.11 and HIPERLAN/2 frequency bands. Hu [7] reported a novel rectangle tree fractal structure which constituted with superposition of a number of rectangular patches. Ultra wide band performance obtained by embedding defects on the ground plane and band rejection characteristics achieved through inserting three U-slots on the fractal tree shaped patch structure. A novel triple notch UWB antenna reported by Tang and Yang [8] which have a circular patch structure with a partially truncated ground plane. To incur band rejection characteristics, a square ring short stub loaded resonator embedded. Amiri [9] investigated an inverted triangle-shaped patch with the trapezoid shaped ground plane for extreme wide band operation. The dual rejection characteristic for $\mathrm{C}$ and WLAN bands obtained through embedding a pair of L-shaped slots in radiating structure. A novel modified octahedron shaped structure with dual rejection band characteristics reported by Mishra and Shau [10]. Ding and Wong [11] communicated an elliptical UWB antenna with single band rejection. The overall size of this antenna reduced through cutting a half elliptical opening from the main radiator. Das [12] reported a low-cost and simple rectangular monopole antenna in which single, double as well as triple notched bands achieved by fluctuating spiral slot length with a median frequency of $3.57 \mathrm{GHz}, 5.12 \mathrm{GHz}$, and $8.21 \mathrm{GHz}$ respectively. S. Yadav [13] communicated a rectangular shaped radiator with a modified ground plane. The bandwidth of this structure extended from $5.0 \mathrm{GHz}$ to $25.5 \mathrm{GHz}$. Single WLAN band rejection obtained by etching an L-shaped slot in the radiating patch structure.

In this communication, a design and performance of a planar CPW feed edge truncated circular patch having triple band-notched characteristics have discussed. Two U-shaped slots in the radiating patch and an inverted U-shaped slot in the feed line has introduced one by one to obtain the triple band-notched characteristics. The WI-MAX, WLAN, and ITU $8.0 \mathrm{GHz}$ bands cater electromagnetic interference with the UWB communication system; hence the rejection of 
these bands has targeted in this proposed work. A reflector is also applied beneath the radiating structure to incur improved gain performance.

\section{Antenna Design and Analysis}

Fig. 1(a) depicts the top view of the CPW feed edge truncated circular patch with triple band notch characteristics. A $1.59 \mathrm{~mm}$ thick glass epoxy FR4 with relative permittivity $\left(\varepsilon_{\mathrm{r}}\right) 4.4$ and loss tangent $=0.025$ is applied as a substrate for the fabrication. The overall dimension of proposed antenna is $30 \mathrm{~mm} \times 20 \mathrm{~mm} \mathrm{x}$ $1.59 \mathrm{~mm}$. The optimized design parameters of the antenna depict in Table 1 . The prototype developed at this stage has shown in Fig. 1(b). The measurements of this antenna carried out with available R\&S made VNA ZVA 40. The simulated and measured variation of VSWR of this antenna with frequency has shown in Fig. 2.

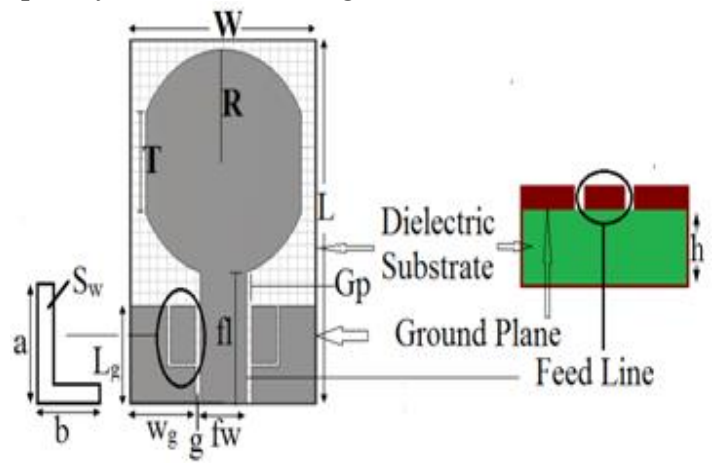

(a)

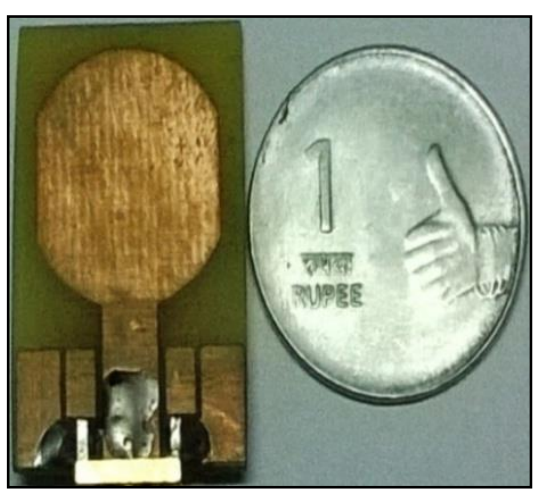

(b)

Figure 1: Geometrical model and prototype of CPW fed UWB antenna with its parameters

Table 1: Optimized dimensions of proposed antenna

\begin{tabular}{cc}
\hline Dimension of proposed Antenna & $\begin{array}{c}\text { Value } \\
\text { (in mm) }\end{array}$ \\
\hline Size of the Substrate $(\mathrm{L} \times \mathrm{W})$ & $30 \times 20$ \\
Radius of the Patch $(\mathrm{R})$ & 9.3 \\
Truncated length parallel to $\mathrm{Y}$ axis $(\mathrm{T})$ & 8.5 \\
Width of the feed line $\left(\mathrm{f}_{\mathrm{w}}\right)$ & 5.00 \\
Gap between patch and ground $\left(\mathrm{G}_{\mathrm{p}}\right)$ & 1.80 \\
Gap between feed line and ground $(\mathrm{g})$ & 0.50
\end{tabular}
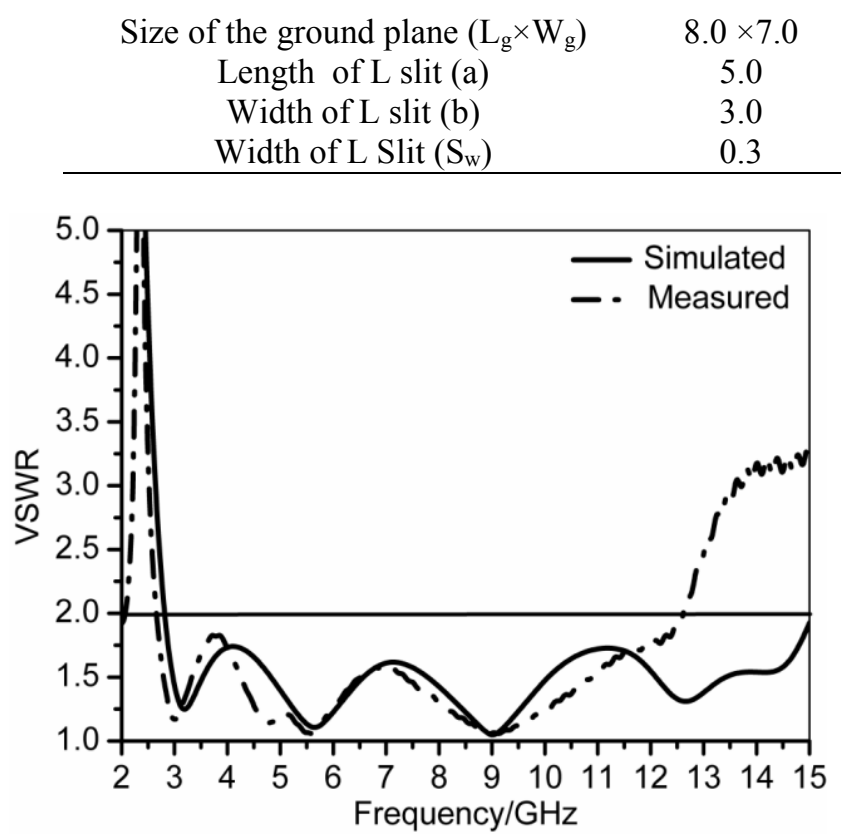

Figure 2: VSWR curve of CPW fed UWB antenna

The measured result provides an excellent matching between the antenna and feed line at frequencies $3.02 \mathrm{GHz}$, $5.56 \mathrm{GHz}$, and $9.12 \mathrm{GHz}$; whereas the simulation result appears that the considered antenna operates efficiently at frequencies $3.19 \mathrm{GHz}, 5.62 \mathrm{GHz}$ and $9.04 \mathrm{GHz}$. A sound agreement occurs between simulation and measured results. The gain of the present structure is around $1.5 \mathrm{dBi}$, which is very low for any practical use. To avoid electromagnetic interference, the refusal of these bands allocated for WLAN /WI-Max and ITU $8 \mathrm{GHz}$ communication systems could not be attained with above geometry. Therefore, this antenna is further modified in different steps to improve its performance.

\subsection{Compact Planar CPW fed UWB Antenna with band notch characteristics}

The above ultra-wide band patch antenna has modified in three separate steps as shown in Figs. 3 (a) -3 (c). The Performance of antenna under each step of modification has obtained distinctly. In each of these figures, a U-shaped slot of different dimensions has introduced at different locations. The Introduction of these inserted slots provides a separate band notch characteristics. Selection of slot length is an important parameter for achieving band notch characteristics. The desired rejection frequency band has achieved by varying the slot length. The appropriate design of band notch component obtained using the following relation [14-15]:

$$
f_{\text {notch }}=\frac{c}{2 L_{\text {eff }} \sqrt{\varepsilon_{\text {eff }}}}
$$

$\mathrm{L}_{\mathrm{eff}}=$ Total effective length of $\mathrm{U}$ slot $=2$ Length + Width - Slot width (S) \&

$$
\varepsilon_{\text {eff }}=\text { effective dielectric constant }=\frac{\varepsilon_{\mathrm{r}}+1}{2}
$$

The optimization of distant slot widths has been done by applying CST Microwave Studio EM simulation software. The parametric analysis of different slot widths 
has given in Figs. 4 (a) -4 (c) \& in Table 2. The width of the U-slot $\left(\mathrm{S}_{1}\right)$ varies from $0.20 \mathrm{~mm}$ to $1.00 \mathrm{~mm}$ and shifting of notch band can be detected from lower to higher frequency side. The slot width $\left(S_{1}\right)$ is tuned to $0.40 \mathrm{~mm}$ to achieve intended rejection band. Similar effects of variation of different $U$ slot widths $\left(\mathrm{S}_{2} \& \mathrm{~S}_{3}\right)$ have presented in Table 2 . The slot widths $\mathrm{S}_{1}, \mathrm{~S}_{2}$ and $\mathrm{S}_{3}$ have tuned to $0.40 \mathrm{~mm}$, $1.35 \mathrm{~mm}$ and $0.70 \mathrm{~mm}$ respectively to achieve intended rejection band.

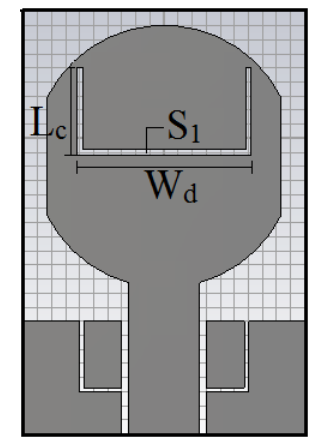

(a) Antenna with Slot 1

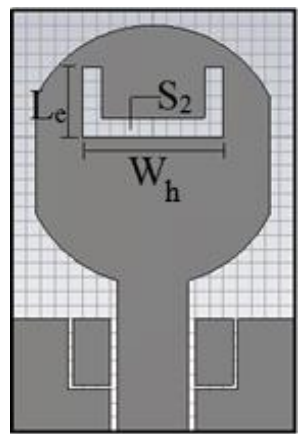

(b)Antenna with Slot 2

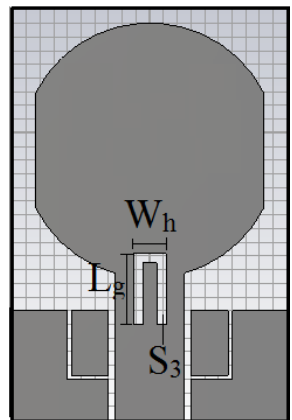

(c)Antenna with Slot 3

Figure 3: Design of CPW fed UWB antennas with slot 1, 2 and 3

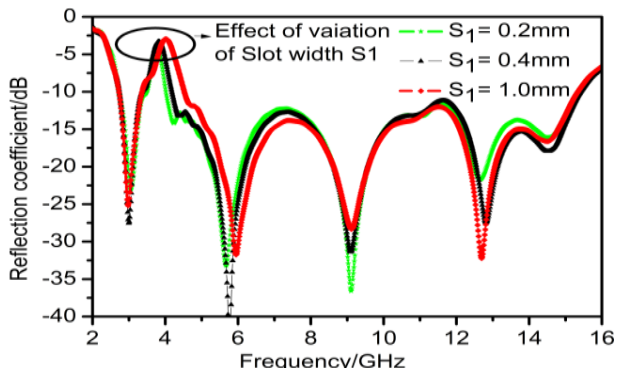

(a)

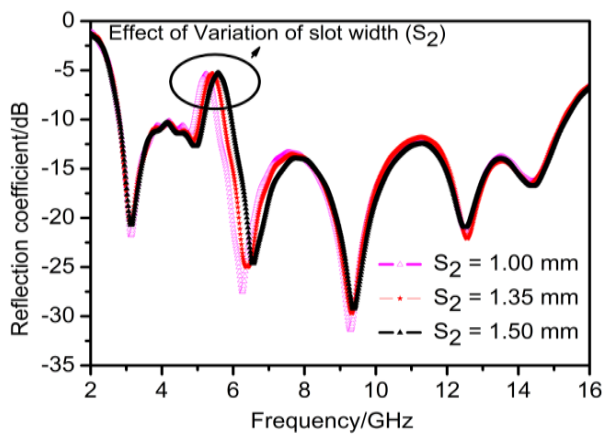

(b)

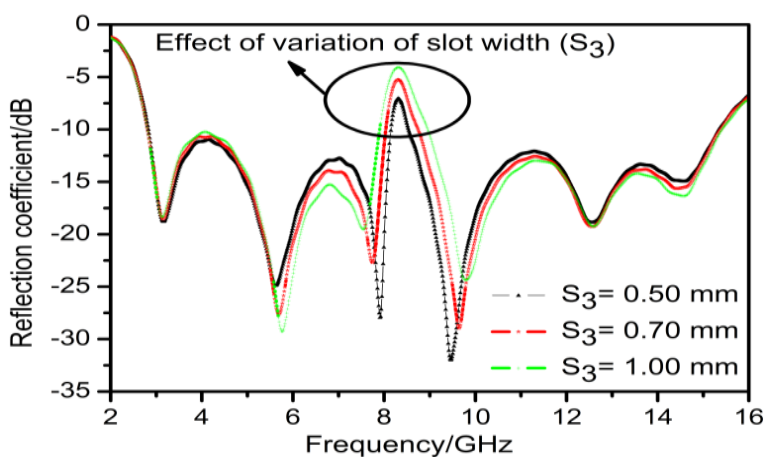

(c)

Figure 4: Simulated Reflection coefficient against frequency for proposed UWB antenna with various $U$ slot widths (a) $S_{1}$, (b) $S_{2}$, (c) $S_{3}$.

Table 2: Parametric study of variation of different Uslots width $\left(\mathrm{S}_{1}, \mathrm{~S}_{2}, \mathrm{~S}_{3}\right)$

\begin{tabular}{llll}
\hline \multirow{2}{*}{ Slot width } & $\begin{array}{l}\text { Notch band } \\
\text { impedance } \\
\text { bandwidth }\end{array}$ & $\begin{array}{c}\text { Central } \\
\text { frequency }\end{array}$ \\
\hline \multirow{3}{*}{$\mathrm{S}_{1}$} & $0.20 \mathrm{~mm}$ & $3.49-4.01 \mathrm{GHz}$ & $3.76 \mathrm{GHz}$ \\
& $0.40 \mathrm{~mm}$ & $3.37-4.16 \mathrm{GHz}$ & $3.83 \mathrm{GHz}$ \\
& $1.00 \mathrm{~mm}$ & $3.37-4.52 \mathrm{GHz}$ & $4.01 \mathrm{GHz}$ \\
$\mathrm{S}_{2}$ & $1.00 \mathrm{~mm}$ & $4.91-5.54 \mathrm{GHz}$ & $5.23 \mathrm{GHz}$ \\
& $1.35 \mathrm{~mm}$ & $5.05-5.75 \mathrm{GHz}$ & $5.41 \mathrm{GHz}$ \\
& $1.50 \mathrm{~mm}$ & $5.17-5.94 \mathrm{GHz}$ & $5.56 \mathrm{GHz}$ \\
$\mathrm{S}_{3}$ & $0.50 \mathrm{~mm}$ & $8.15-8.52 \mathrm{GHz}$ & $8.31 \mathrm{GHz}$ \\
& $0.70 \mathrm{~mm}$ & $8.04-8.73 \mathrm{GHz}$ & $8.31 \mathrm{GHz}$ \\
& $1.00 \mathrm{~mm}$ & $7.90-8.94 \mathrm{GHz}$ & $8.32 \mathrm{GHz}$ \\
\hline
\end{tabular}

Since these slots have located at different positions of the radiating structure and are not overlapped with each other; hence it has decided to place them together with the patch geometry. These three slots optimize in terms of their location and dimensions to reduce the coupling effects. The dimension of introducing U-shaped slot has shown in Fig. $3(\mathrm{a})$ are $\mathrm{L}_{\mathrm{c}}=6.2 \mathrm{~mm}, \mathrm{~W}_{\mathrm{d}}=12.4 \mathrm{~mm}, \mathrm{~S}_{1}=0.4 \mathrm{~mm}$ and it provides the band notch characteristics for central frequency $3.78 \mathrm{GHz}$ corresponds to WLAN (3.44 to $4.15 \mathrm{GHz}$ ) system. The dimension of the U-shaped slot has shown in Fig. $3(\mathrm{~b})$ are $\mathrm{L}_{\mathrm{e}}=5 \mathrm{~mm}, \mathrm{~W}_{\mathrm{f}}=10 \mathrm{~mm}, \mathrm{~S}_{2}=1.35 \mathrm{~mm}$ and it provides the band notch characteristics for WI-MAX $(5.07$ to $5.73 \mathrm{GHz}$ ) systems with central frequency $5.48 \mathrm{GHz}$. An inverted $U$ slot has inserted in the feed line having dimensions $\mathrm{L}_{\mathrm{g}}=5.2 \mathrm{~mm}, \mathrm{~W}_{\mathrm{h}}=2.4 \mathrm{~mm}$ and $\mathrm{S}_{3}=0.70 \mathrm{~mm}$ which has shown in Fig. 3 (c) and it develops a band notch characteristics for ITU band $(8.04$ to $8.69 \mathrm{GHz})$ with central frequency $8.21 \mathrm{GHz}$. In this way, each of these inserted slots in the CPW fed UWB antenna is functioning independently and provides separate band-notch characteristics as shown in Fig. 5. The modified antenna with all three slots together has shown in Fig. 6. The variation of simulated and measured VSWR with frequency has shown in Fig. 7 and it exhibits triple band notch characteristics. The measured results provide a wide impedance bandwidth which extends between frequency range $2.70 \mathrm{GHz}$ to $14.50 \mathrm{GHz}$ for $\mathrm{VSWR}<2$, with the triple rejected band in the frequency ranges of 3.37-4.00 GHz, 
5.20-5.72 GHz, 8.04-8.72 GHz for VSWR > 2. A reasonable agreement between simulated and measured VSWR values is realizing.

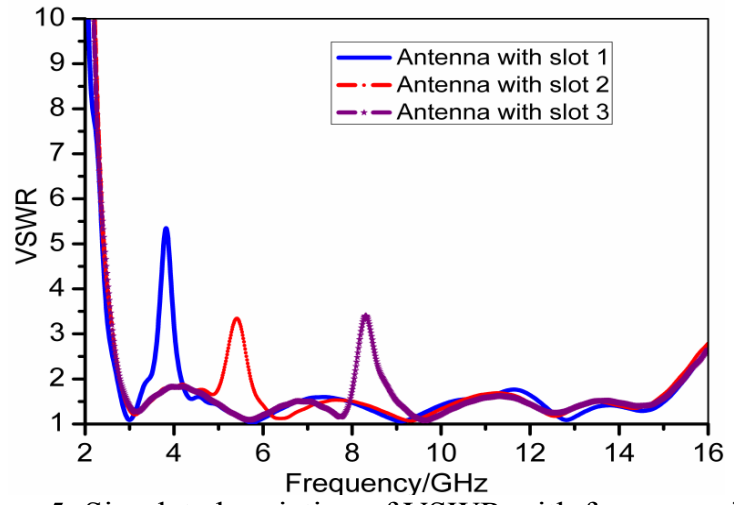

Figure 5: Simulated variation of VSWR with frequency in different considered antennas.

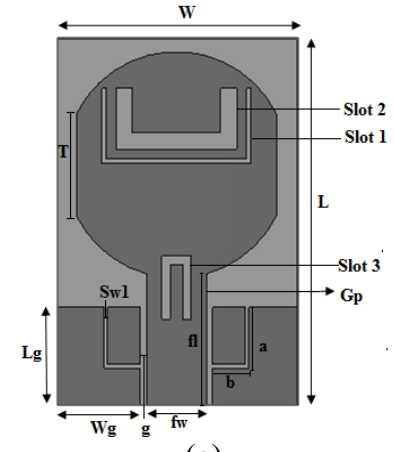

(a)

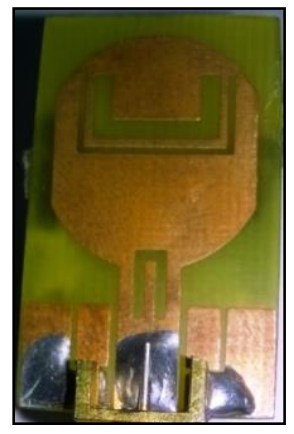

(b)
Figure 6: Geometry \& prototype of proposed UWB antenna with triple band notched

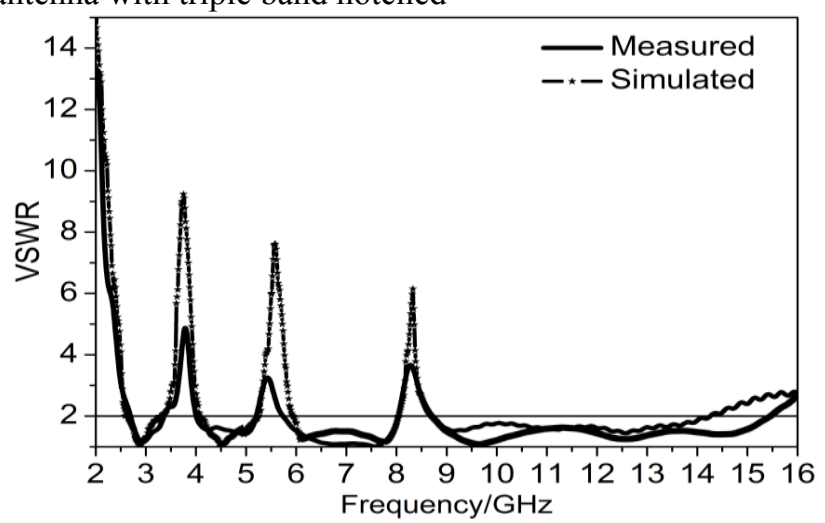

Figure 7: Variation of measured/simulated VSWR of the proposed UWB antenna

The surface current distributions at a different stop and pass band frequencies have shown in Fig. 8. In stop bands, strong surface current distribution has detected around the boundaries of the U-slots, but directions of current on the inner and outer edge is opposite in nature. Hence, these currents cancel out the effect of each other and prevent the antenna to radiate at these frequencies. Accordingly, the radiated field in the far field regions turns frail. This behavior of the surface current distributions describes the creations of the different bands notch in the far-field region, which has depicted in Figs. 8(b) $(3.5 \mathrm{GHz}$, WI-MAX IEEE 802.16 band notch), 8(d) (5.5 GHz, WLAN IEEE 802.11 $\mathrm{a} / \mathrm{h} / \mathrm{j} / \mathrm{n}$ band notch) and $8(\mathrm{f})(8 \mathrm{GHz}, \mathrm{X}$-band downlink satellite system) respectively. At a working band frequency of $2.94 \mathrm{GHz}$, current mainly concentrates on the feed line and on the edge of the L-slits which can see in Fig. 8 (a). This suggests that the U-slots do not have much impact on the performance of this resonant frequency. From Figs. 8 (c) and $8(\mathrm{e})$, it can be observed that both pass band frequencies (4.95 GHz and $7.57 \mathrm{GHz}$ ) have combined effect of strong surface current distributions concentration around the feed line and U-slots. The simulated/measured two-dimensional Co and Cross-polarized radiation patterns in elevation and azimuth planes at three frequencies namely $2.94 \mathrm{GHz}, 4.95$ $\mathrm{GHz}$, and $7.57 \mathrm{GHz}$ has shown in Figs. 9 (a) to 9 (c). It is realized that these two-dimensional radiation patterns are nearly omnidirectional and resembles with a typical monopole antenna. The gain of this antenna is still significantly low nearly (1-4) dBi while directivity of an antenna is inadequate. The enhancement of directivity and gain performances of this present structure is next aim.

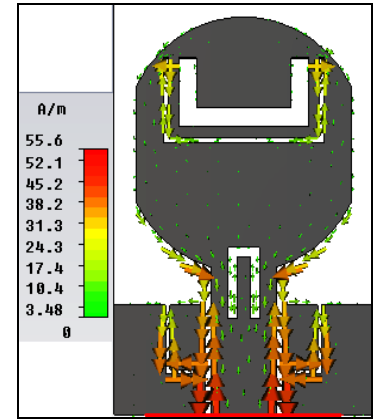

(a) $2.94 \mathrm{GHz}$

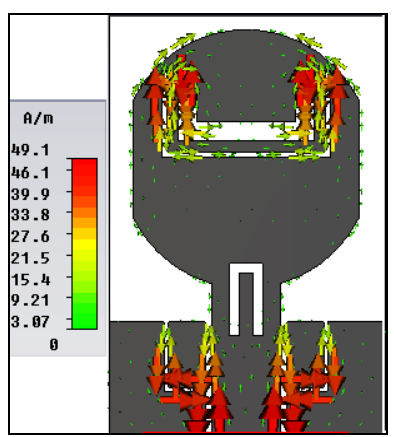

(c) $4.95 \mathrm{GHz}$

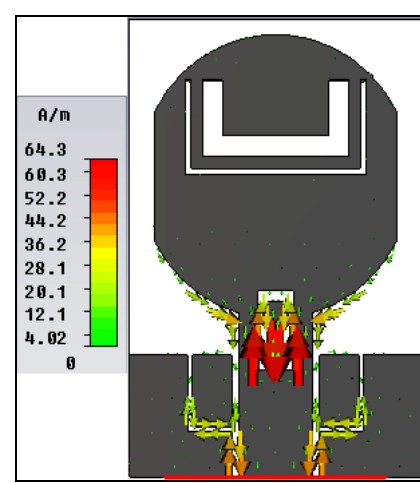

(e) $7.57 \mathrm{GHz}$

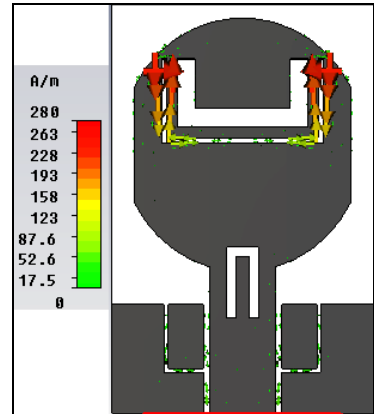

(b) $3.78 \mathrm{GHz}$

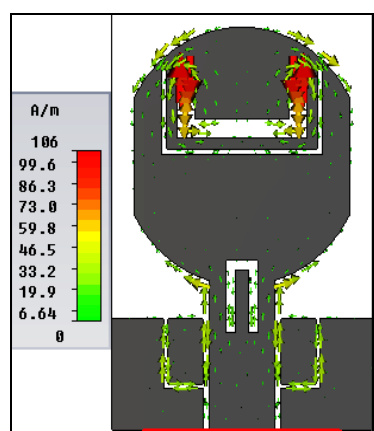

(d) $5.48 \mathrm{GHz}$

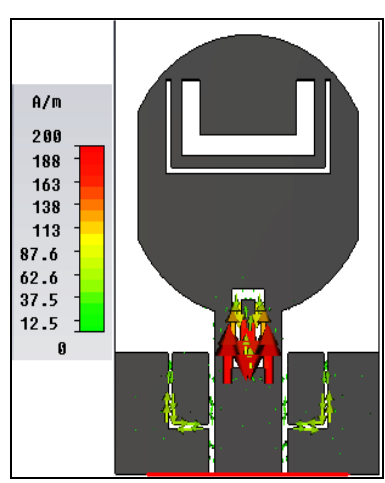

(f) $8.21 \mathrm{GHz}$
Figure 8: Current distribution at different pass band resonant frequencies as well as notch band central frequencies 

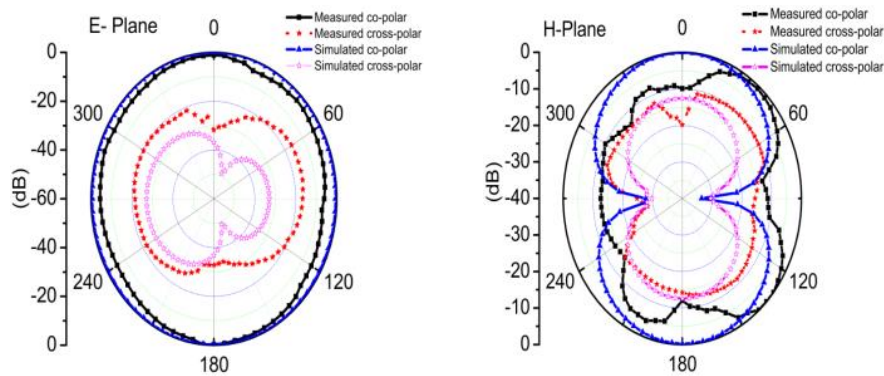

(a) $2.94 \mathrm{GHz}$
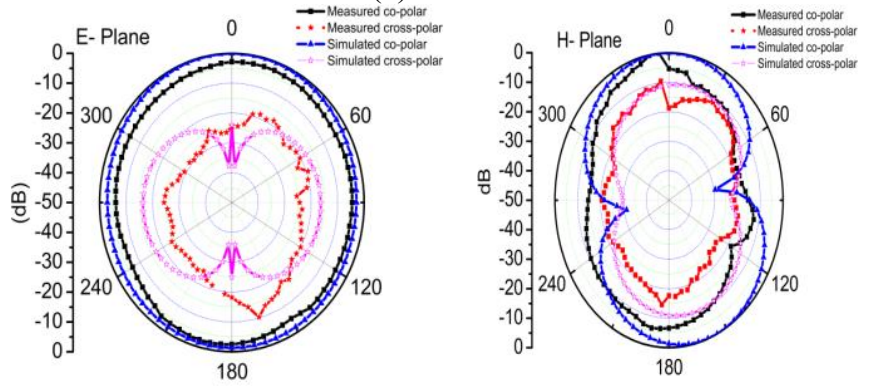

(c) $4.95 \mathrm{GHz}$
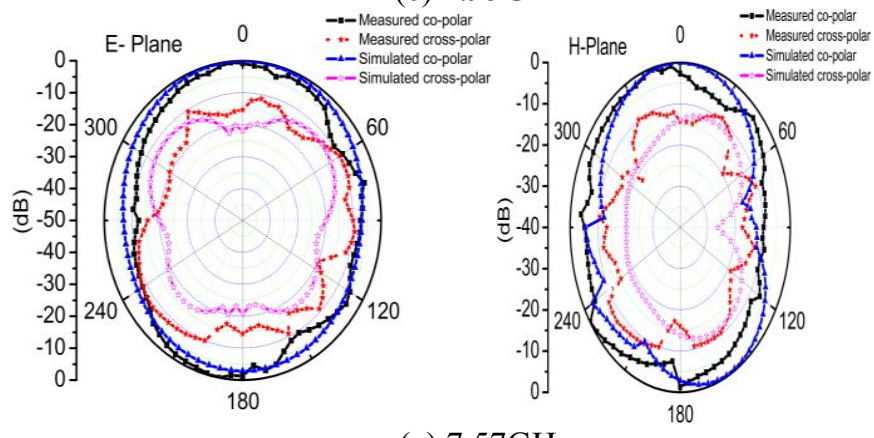

(e) $7.57 \mathrm{GHz}$

Figure 9: Measured 2D radiation pattern at various resonant frequencies

\subsection{Compact planar CPW fed UWB antenna with reflector}

In this section, we apply a thin metallic sheet having dimension $50 \mathrm{~mm} \times 50 \mathrm{~mm}$ beneath the radiating element to improve the overall gain and directivity of the antenna. This metal sheet acts as a reflector and place $32 \mathrm{~mm}$ beneath the proposed structure where the condition of constructive interference of radiations satisfies. Introduction of this thin metallic plate improves the gain and directivity of the antenna without altering other antenna parameters. The proposed CPW fed antenna with reflector has shown in Fig. 10.

The simulated and measured VSWR variation of the antenna as the function of frequency has shown in Fig. 11. The measured results present a wide impedance bandwidth extended between frequencies $2.71 \mathrm{GHz}$ to $12.92 \mathrm{GHz}$ for VSWR $<2$ with triple rejection bands in the frequency ranges lying between 3.456 to $3.988 \mathrm{GHz}, 5.27$ to 6.032 $\mathrm{GHz}, 7.88$ to $8.65 \mathrm{GHz}$ for VSWR $>2$. The measured results show that the considered antenna has an excellent matching at three frequencies viz. $2.81 \mathrm{GHz}, 5.56 \mathrm{GHz}$, and $9.12 \mathrm{GHz}$. A marginal difference present between simulated and measured results is perhaps due to fabrication limitations of the radiating structure. The simulated/measured Co and Cross-polarized far-field radiation patterns in the elevation and azimuth planes at frequencies $2.81 \mathrm{GHz}, 5.01 \mathrm{GHz}$, and $7.57 \mathrm{GHz}$ are shown in Fig. 12. These figures indicate that the radiations are more directed in the front direction of the radiator. The measured radiation patterns are unidirectional in a lower frequency range.

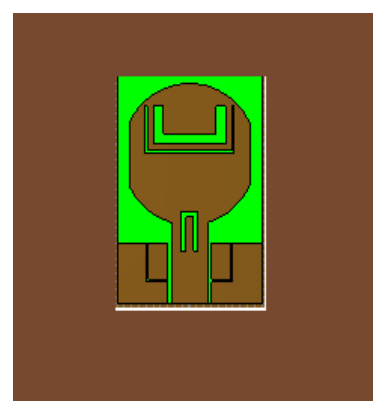

(a)

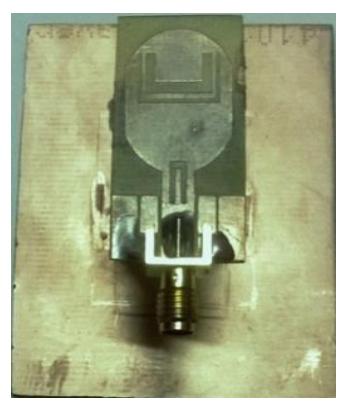

(b)
Figure 10: Geometrical \& fabricated proposed CPW fed UWB antenna with reflector.

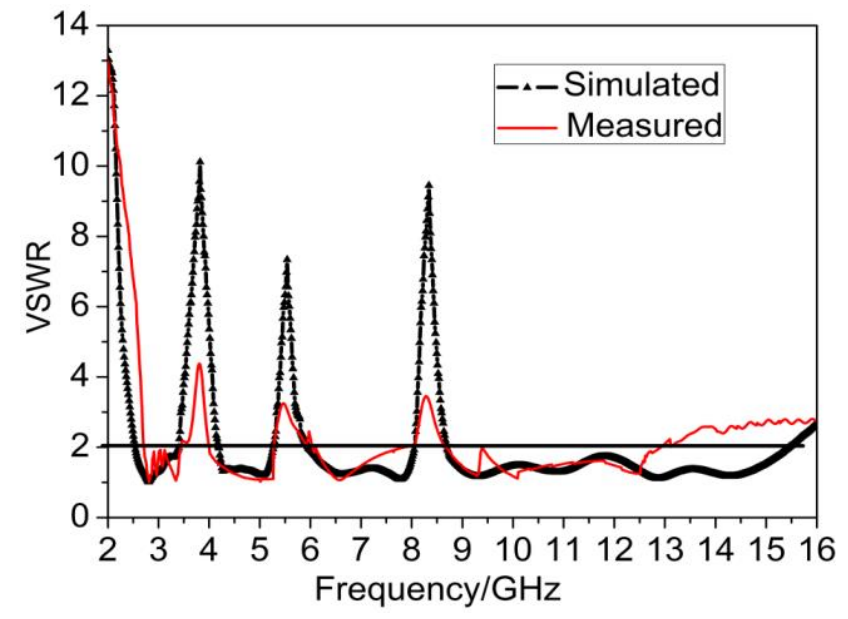

Figure 11: Measured and simulated VSWR of the proposed UWB antenna with reflector.
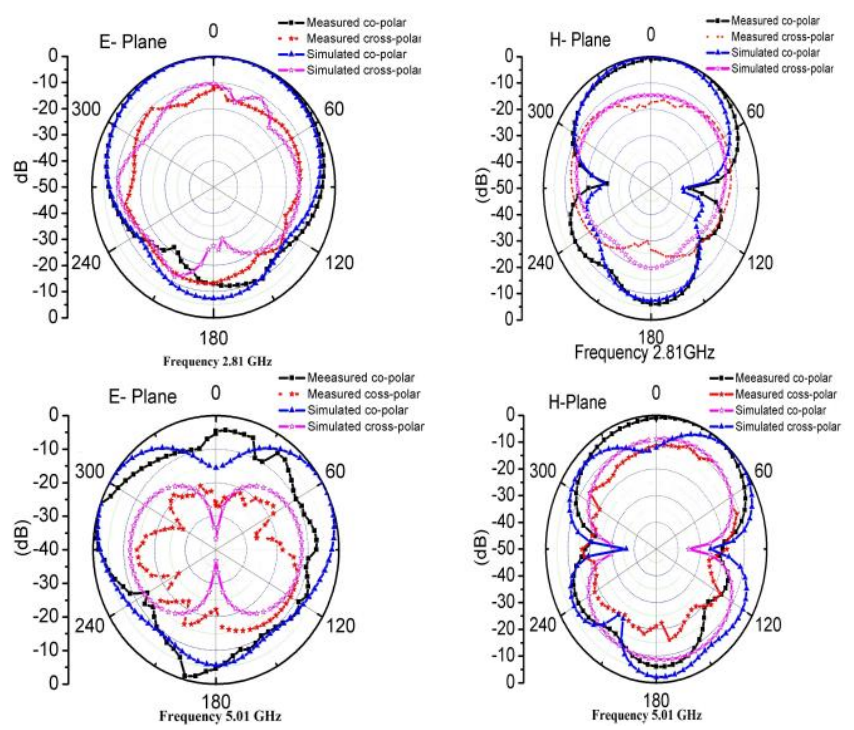

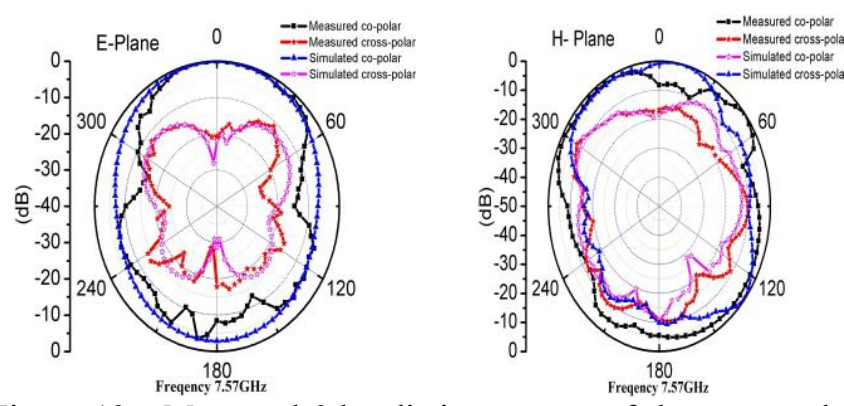

Figure 12: Measured 2d radiation pattern of the proposed antenna with reflector at different frequencies.

Since the distance between the antenna and reflector select to meet out the conditions of constructive interference, the directivity and gain of the antenna have increased noticeably in the forward direction. Fig. 13 shows the variation of gain with frequency in both cases, i.e. with and without a reflector. This figure indicates that gain of the antenna in the operating frequency range is within 6 to 10 $\mathrm{dBi}$ range, which is much higher than the previous case (without reflector). The maximum gain of proposed antenna is close to $9.9 \mathrm{dBi}$ at $7.4 \mathrm{GHz}$. The fair agreement is realized between simulated and measured gain results. The proposed antenna also presents good radiation efficiency (better than $80 \%$ across the UWB band) except in the three rejection bands. The simulated antenna efficiency at three notch central frequencies 3.82, 5.54 and $8.34 \mathrm{GHz}$ are $31 \%, 47 \%$, and $21 \%$ respectively which has shown in Fig. 14.

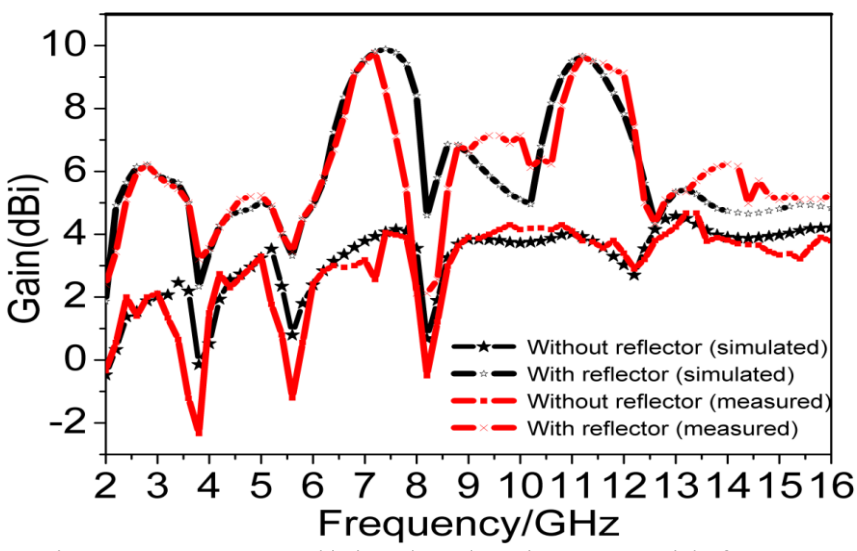

Figure 13: Measured/Simulated Gain curve with frequency with and without reflector of proposed Antenna

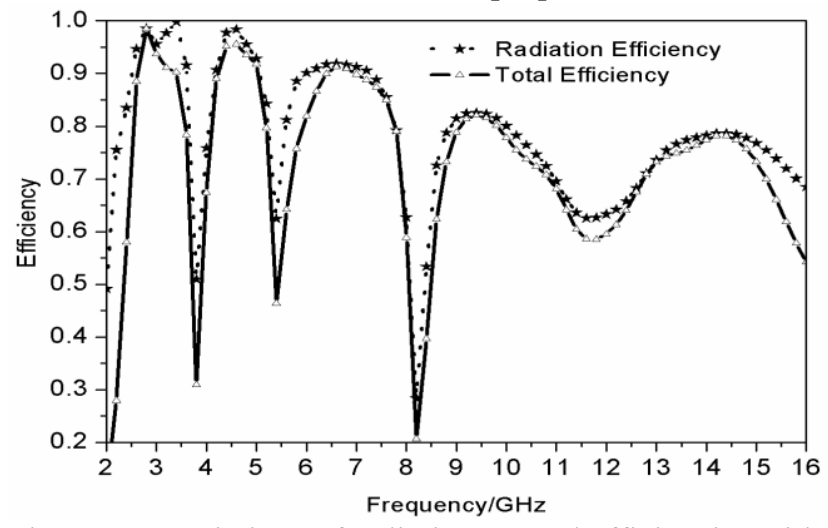

Figure 14: Variations of radiation \& total efficiencies with frequency of proposed antenna with reflector

\section{Discussion}

The comparison of performance of different recent antenna designs with proposed antenna is given in Table 3 which demonstrates that the proposed antenna structure has a compact size offers larger bandwidth with triple bandnotched characteristics and gain values.

Table 3: Comparisons of performance of the Proposed Antenna with other multi band designed antenna

\begin{tabular}{|c|c|c|c|c|}
\hline Ref. & $\begin{array}{c}\text { Size } \\
\left(\mathrm{mm}^{2}\right)\end{array}$ & $\begin{array}{c}\text { Operating } \\
\text { frequency band } \\
(\mathrm{GHz})\end{array}$ & $\begin{array}{l}\text { Frequency } \\
\text { range of } \\
\text { the notched } \\
\text { bands } \\
(\mathrm{GHz})\end{array}$ & $\begin{array}{l}\text { Maximum } \\
\text { Gain }(\mathrm{dBi})\end{array}$ \\
\hline [9] & $30 \times 30$ & 2.90-21.80GHz, & $\begin{array}{c}3.65-4.38 \\
\mathrm{GHz} \\
4.93-6.06 \\
\mathrm{GHz} \\
3.30-3.70\end{array}$ & $\begin{array}{l}\text { Less than } \\
4 \mathrm{dBi}\end{array}$ \\
\hline$[10]$ & $40 \times 30$ & 2.4-19.5 GHz, & $\begin{array}{c}\mathrm{GHz}, \\
5.15-5.85 \\
\mathrm{GHz} .\end{array}$ & $\begin{array}{l}\text { Less than } \\
4 \mathrm{dBi}\end{array}$ \\
\hline [11] & $30 \times 28$ & $2.70-13.10 \mathrm{GHz}$ & $\begin{array}{c}5.00-6.00 \\
\text { GHz. }\end{array}$ & ---- \\
\hline$[13]$ & $50 \times 50$ & $2.30-11.00 \mathrm{GHz}$ & $\begin{array}{c}\text { 6.20-6.90 } \\
\text { GHz. }\end{array}$ & $4-5 \mathrm{dBi}$ \\
\hline [16] & $50 \times 42$ & UWB range & $\begin{array}{c}3.30-3.80 \\
\mathrm{GHz} \\
5.15-5.825 \\
\mathrm{GHz} \\
7.10-7.90 \\
\mathrm{GHz} .\end{array}$ & $5.5 \mathrm{dBi}$ \\
\hline [17] & $40 \times 40$ & $2.80-11.34 \mathrm{GHz}$ & $\begin{array}{c}5.725- \\
5.825 \mathrm{GHz}, \\
8.025- \\
8.400 \mathrm{GHz} .\end{array}$ & $\begin{array}{c}\text { Less than } \\
4 \mathrm{dBi}\end{array}$ \\
\hline [18] & $40 \times 31$ & $2.93-10.04 \mathrm{GHz}$ & $\begin{array}{c}3.31-3.78 \\
\mathrm{GHz} \\
5.33-5.77 \\
\mathrm{GHz} \\
7.24-7.72 \\
\mathrm{GHz} .\end{array}$ & $7.4 \mathrm{dBi}$ \\
\hline $\begin{array}{c}\text { Prop } \\
\text { osed } \\
\text { Ante } \\
\text { nna }\end{array}$ & $30 \times 20$ & $2.70-14.50 \mathrm{GHz}$ & $\begin{array}{c}3.37-4.00 \\
\mathrm{GHz}, \\
5.20-5.72 \\
\mathrm{GHz}, \\
8.04-8.72 \\
\mathrm{GHz} .\end{array}$ & $\begin{array}{c}3-4 \mathrm{dBi} \\
\text { (without } \\
\text { reflector), } \\
9.88 \mathrm{dBi} \\
\text { (With ref.) }\end{array}$ \\
\hline
\end{tabular}

\section{Conclusions}

This paper reports the design and performance of the UWB antenna with triple band-notched characteristics and improved gain. Proposed CPW fed patch antenna has two Ushaped slots on the patch and an inverted U-shaped slot in feed line with metallic reflector beneath the antenna structure. The three rejection bands have obtained by 
inserting three U-slots of different sizes and at different locations in the radiator. The proposed antenna has probed in terms of VSWR, surface current distribution, efficiency, gain, and radiation patterns. The maximum gain of the antenna is close to $9.88 \mathrm{dBi}$ at $7.4 \mathrm{GHz}$. The effect of the energy storage slots and reflector has been fortuitously examined. A sharp reduction is also actualized in the gain and radiation efficiency values over the notched frequency bands. This antenna is a useful structure for modern ultra wideband communication systems except for the $3.5 \mathrm{GHz}$ WIMAX, IEEE $802.11 \mathrm{a} / \mathrm{h} / \mathrm{j} / \mathrm{n}$ WLAN and ITU $8 \mathrm{GHz}$ systems.U-shaped monopole planar antenna having eight shaped ring slot in patch and eight shaped ring in ground plane with metallic reflector beneath the ground plane provide triple band performance. The impedance bandwidths in these bands extend from $2.280 \mathrm{GHz}$ to $2.545 \mathrm{GHz}, 2.660$ $\mathrm{GHz}$ to $2.776 \mathrm{GHz}$ and $3.83 \mathrm{GHz}$ to $5.956 \mathrm{GHz}$ respectively. Desired flat gain (close to $5 \mathrm{dBi}$ ), better directivity and good radiation patterns in the desired frequency range are also realized with proposed geometry. The maximum gain of the antenna is close to $5.56 \mathrm{dBi}$ at $2.4 \mathrm{GHz}$. This antenna may be proved a useful structure for modern wireless communication systems, including in devices like Bluetooth, WLAN, WI-MAX and lower band of UWB communication systems.

\section{Acknowledgements}

Authors are thankful to DEIT, New Delhi for the financial support provided for the present work. Authors also extend their sincere thanks to Mr. V.V. Srinivasan, ISAC, and Bangalore for his valuable help in this work.

\section{References}

[1] FCC. Revision of Part 15 of the Commission's Rules Regarding Ultra-Wideband Transmission Systems FCC, Report FCC 02-48. Washington, DC, USA: FCC, 2002.

[2] K. Siwiak, D. McKeown, Ultra-wideband Radio Technology, John Wiley \& Sons Ltd, The Artium, Southern Gate, Chichester, West Sussex PO 198 SQ, England, April 2004.

[3] X. Shen, M. Guizani, R. C, Qiu, T. Le-Ngoc, Ultrawideband Wireless Communication and Networks, John Wiley \& Sons Ltd, The Artium, Southern Gate, Chichester, West Sussex PO 198 SQ, England, 2006.

[4] F.-B. Zarrabi, Z. Mansouri, N.-P. Gandji, H. Kuhestani, Triple-notch UWB monopole antenna with fractal Koch and T-shaped stub, $A E U$ International Journal of Electronics and Communication 70: 64-69, 2016.

[5] M. Sharma, Y.-K. Awasthi, H. Singh, R. Kumar, S. Kumari, Compact printed high rejection triple bandnotch UWB antenna with multiple wireless applications, Engineering Science and Technology 19: 1626-1634, 2016.
[6] A. Syed, R.-W. Aldhaheri, A very compact and low profile UWB planar antenna with WLAN band rejection, The Scientific World Journal 2016 Article ID 3560938:1-7, 2016. doi:10.1155/2016/3560938.

[7] Z. Hu, Y. Hu, Y. Luo, W. Xin, A novel rectangle tree fractal UWB antenna with dual band-notched characteristics, Progress In Electromagnetics Research C 68: 21-30, 2016.

[8] C. Tang, N. Yang, A novel compact UWB antenna with triple notched bands using square ring short stub loaded resonator, Progress In Electromagnetics Research letters 58: 17-22, 2016.

[9] Z. Amiri, S. Movagharnia, M. Masoumi, M. Shokry, B.-S. Virdee, Extremely wideband printed monopole antenna with dual rejection bands, Microw. Opt. Technol. Lett. 58: 908-911, 2016.

[10] G. Mishra, S. Sahu, Modified octahedron shaped antenna with parasitic loading plane having dual band notch characteristics for UWB applications, Int $J R F$ and Microwave Comp Aid Eng 26: 426-434, 2016.

[11] W. Ding, G. Wang, Miniaturized band-notched ultrawideband antenna, Microw. Opt. Technol. Lett. 58: 2780-2786, 2016.

[12] S. Das, D. Mitra, S.-R.-B. Chaudhuri, Design of UWB planar monopole antennas with etched spiral slot on the patch for multiple band-notched characteristics. International Journal of Microwave Science and Technology 2015 Article ID 303215: 1-9, 2015. doi:10.1155/2015/303215.

[13] S. Yadav, A.-K. Gautam, B.-K. Kanaujia, Design of miniaturized single-notch band microstrip patch antenna with enhanced UWB performance, Microw. Opt. Technol. Lett. 58: 1494-1499, 2016.

[14] O.-M. Haraz, A. Elboushi, A.-B. Sebak, Band Rejection Capabilities of UWB Elliptical Slot Antenna with Half Circular and Crescent Ring Shaped Radiators, 2010 IEEE Antennas and Propagation Society International Symposium, Sherton Centre Hotel, Toronto, Canada, pp. 1-4, July 2010 .

[15] K.-G. Jangid, A. Tiwari, V. Sharma, V.-S. Kulhar, V.-K. Saxena, D. Bhatnagar, Circular Patch Antenna with Defected Ground for UWB Communication with WLAN Band Rejection, Defence Science Journal 66(2): 162-167, 2016.

[16] N. Jaglan, B.-K. Kanaujia, S.-D. Gupta, S. Srivastav, Triple band notched UWB antenna design using electromagnetic band gap structures, Progress In Electromagnetics Research C 66: 139-147, 2016.

[17] H.-A. Atallah, A.-B. Abdel Rahman, Y. Yoshitomi, R.-K. Pokharel, Design of dual band-notched CPWfed UWB planar monopole antenna using microstrip resonators, Progress In Electromagnetics Research letters 59: 51-56, 2016.

[18] X. Gong, L. Tong, Y. Tian, B. Gao, Design of a microstrip-fed hexagonal shape UWB antenna with triple notched bands, Progress In Electromagnetics Research C 62: 77-87, 2016. 